\title{
Bicycle Priority Area Recognition Based on GIS: A Case Study of Kochi City
}

\author{
David A. Soltanian \\ Department of Architecture, TKM College of Engineering, Kollam, India \\ sruthyssk[at]gmail.com
}

\begin{abstract}
Cities today face many urban challenges related to high population density. Transportation is one such challenge that results in problems of congestion and pollution, especially with burgeoning private car usage. Cycling is one among the foremost sustainable modes of transportation. The average trip length in Indian cities is convenient for cycling but the share of cycling as a mode of transport has been declining. Creating a bicycle network within the urban areas is the key to encourage the utilization of the bicycle as the daily mode of private transportation. Kochi City Region (KCR) in Kerala was selected as the study area as the share of private vehicles has been increasing and there is a need for a sustainable mode of transportation. The paper focuses on how to identify priority cycling areas in an already developed urban area. The study identifies how to deploy certain geographic information system (GIS) tools along with Multi criteria decision analysis (MCDA) for analyzing multilayered spatial data at the city level. The results confirms that the use of these GIS tools for analyzing various parameters for identifying priority areas for cycling routes is efficient.
\end{abstract}

Keywords: Cycling, Geographic information system, Multi-criteria analysis, Non-motorized transport.

\section{Introduction}

The National Urban Transport Policy (NUTP) and National Mission on Sustainable Habitat (NMSH) have stressed the necessity for an approach that focuses on people and not vehicles. Road design must not increase the dependence on and usage of personal motorized vehicles. This is possible only if cities are built to prioritise the public transport, walking and cycling (NMSH, 2011). Indian cities have a high latent demand for cycle and walking trips, which can be addressed with the introduction of suitable infrastructure, facilities and resources.

The major factors that have led to a decline in the share of bicycles are rising income levels, absence of safe cycling infrastructure, and increased affordability of motorized vehicles (especially two-wheelers). In cities short-distance trips which can be undertaken by bicycles are now being made by cars and two-wheelers instead. The increasing motorization in urban and rural areas has given rise to many negative externalities such as dependence on fossil fuels, GHG emissions, congestion, pollution and the associated health impacts.

The COVID-19 pandemic has reshaped our cities in many ways. While the number of motor vehicles on the road has plummeted during lockdown, an increasing number of people have turned to walking and biking, moving speedily and safely through once congested streets. The shift has brought some visible changes: local air pollution has dropped by up to $60 \%$ globally, and cities that used to be covered with a thick blanket of smog are experiencing their first blue skies in a long time.Creating a bicycle network in the urban areas is the key point to encourage the use of the bicycle as the daily mode of personal transportation Studies about how to determine bicycle routes in cities emerge in various fields (urban geography, transportation, urban planning and urban design) and pay attention on the concerns about health and physical activity, healthy living, sustainable transportation and non-motorized transportation. (Saelens et al. 2003, Huang and Ye 1995, WendelVos et al. 2004, Segadilha and da Penha Sanches 2014, Blečić et al. 2015). Relying on GIS tools, a few studies (Huang and Ye 1995, Rybarczyk and Wu 2010, Milakis and Athanasopoulos 2014) contribute to determine bicycle routes in already developed built environments of densely populated cities.

\section{Literature Review}

Non-motorised modes include walking, bicycle and cycle rickshaw. These modes are not dependent on fossil fuels, and have minimal emissions. Cycling is one of the most sustainable modes of transportation. Cycling is associated with positive externalities like health improvements, congestion reduction, lessening of air pollution and greenhouse gas (GHG) emissions, and minimizing energy use. As part of the efforts related to sustainable development, carbon-free and non-motorized transportation and "healthy" cities, many researches and policy initiatives in most countries promote bicycle use in daily life and a decline in the use of cycles as a mode of transport.

Deploying GIS tools, the researchers about bicycle network planning emphasize the route choice criteria for bicycling in relation to the physical, infrastructural and natural characteristics of settlements (Rybarczyk and Wu 2010) and to the modelling of bicyclists' route preferences by GPS records as well as to cycling demand of population in terms of transport distance and quality of route utilities (SkovPetersen et al. 2018). All determinants can be re-categorized as demand-based and supply-based criteria for bicycle route planning. As part of the demand-based determinants, we can consider business districts, commercial areas, schools and parks and recreational areas. The supply-based determinants can include the data on demographics, level of safety, characteristics of public transportation, road characteristics and existing bicycle routes as these provide available conditions for cycling (Rybarczyk and Wu 2010). 


\section{Aim, Objectives and Scope}

\subsection{Aim}

The aim of the study is to perform a Comprehensive Bicycle route suitability assessment using GIS-Multi criteria analysis method and identify the priority areas that are suitable for cycling.

\subsection{Objectives}

- To study and analyse the various components and methods used for bicycle network planning

- To identify and examine the demand and supply-side determinants for cycling infrastructure.

- To identify the existing determinants for cycling infrastructure in Kochi city.

- To identify suitable areas for cycling in Kochi city through Bicycle route suitability assessment.
3.3 Scope

The study broadly discusses about the importance of cycling in urban areas. The study seeks to provide a case with a methodology using digital analyzing techniques for determining new bicycle networks within dense built environments. The study determines the "most suitable area" for bicycle route using multi-criteria decision analysis in GIS environment

\section{Methodology}

The research is carried out in three stages. In the first stage the background study is discussed, the aim, objectives, scope of the study is formulated. Literature review is discussed in the first stage and the study area is identified. The second stage discusses about the data collection through primary and secondary sources. Major tasks in this stage are interviews, surveys, on-site observations and search for relevant secondary data. In the final stage the suitability assessment is carried out using overlay analysis in GIS. The priority areas for cycling are identified through this suitability assessment.

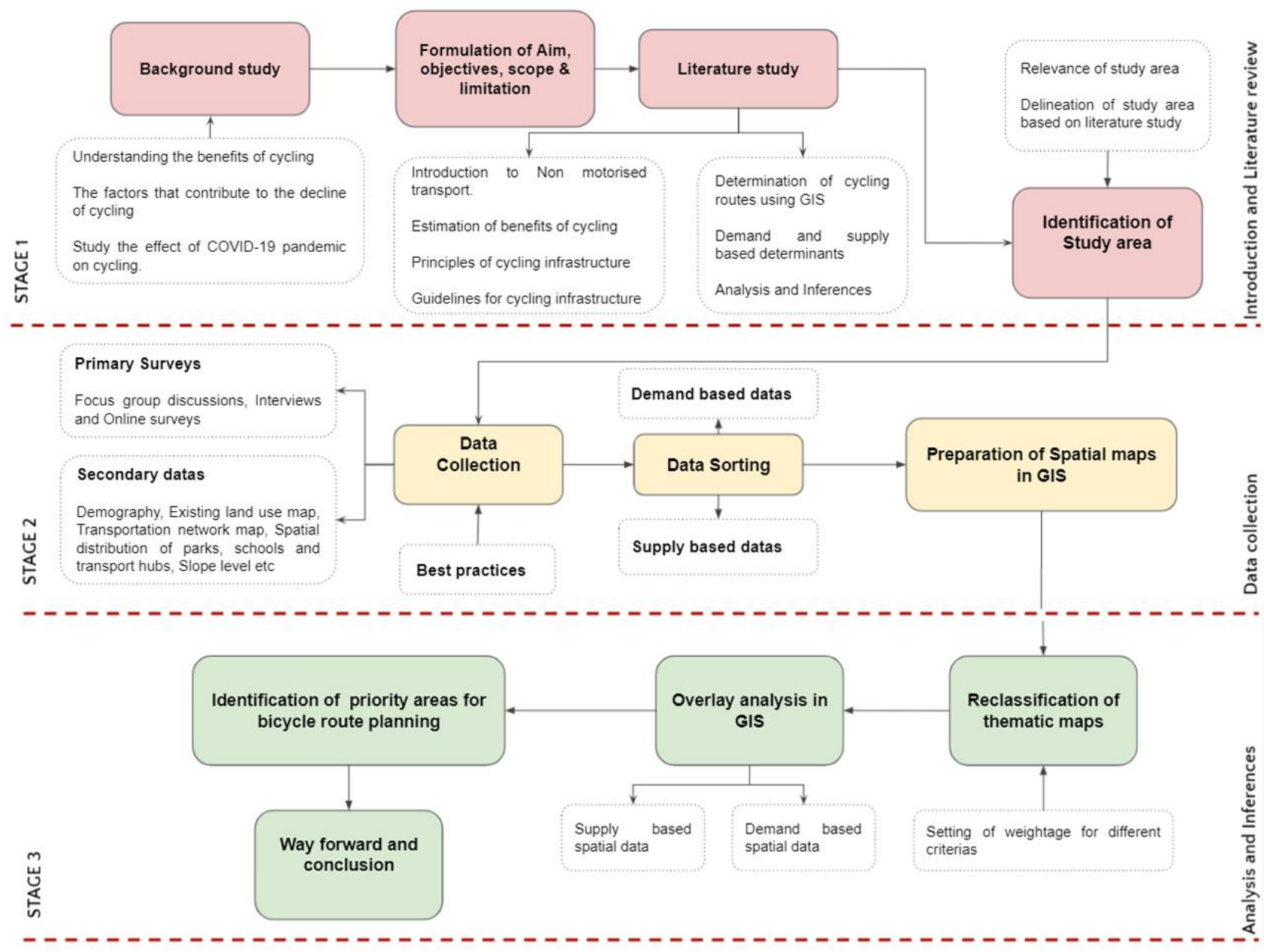

Figure 1: Methodology of the study

\section{Study Area}

The city of Kochi is located on the western coast of India in Ernakulam district of Kerala. Kochi is a cradle of Eurasian culture. Located on the south-western coast of India, the city is more than 500 years. A vibrant cultural hub, this coastal city blends different natural landscapes (backwaters, canals and green cover) and tourism is a major contributor to the 
city's economy. Kochi is also part of India's Smart Cities Mission project.

The city consists of 3 administrative boundaries, namely Cochin Municipal Corporation (CMC), Kochi City Region (KCR) and Greater Cochin Development Authority (GCDA) with a population of 6.46 lakhs, 12.23 lakhs and 20.01 lakhs respectively. The metro is emerging to be the new mode of choice for the city. However, walking and cycling remains a challenge due to lack of safety and Infrastructure for short distance users.

Kochi City Region (KCR) is a contiguous region of land consisting of the areas under the Corporation of Kochi and sixteen other local bodies, including five municipalities in the form of Tripunithura, Kalamassery, Maradu, Eloor and Thrikkakkara.

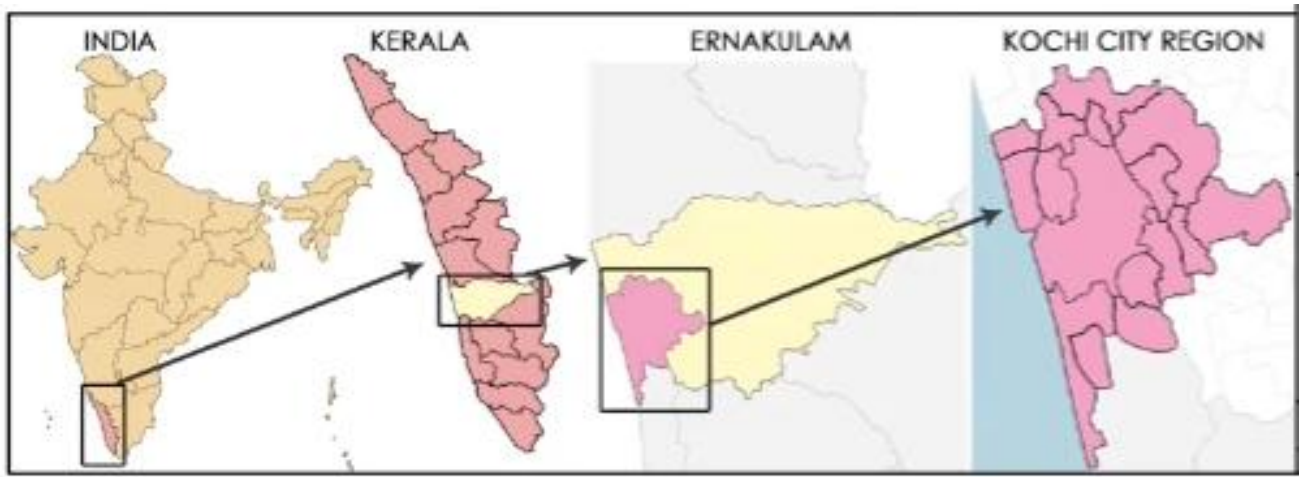

Figure 2: Location of Study area

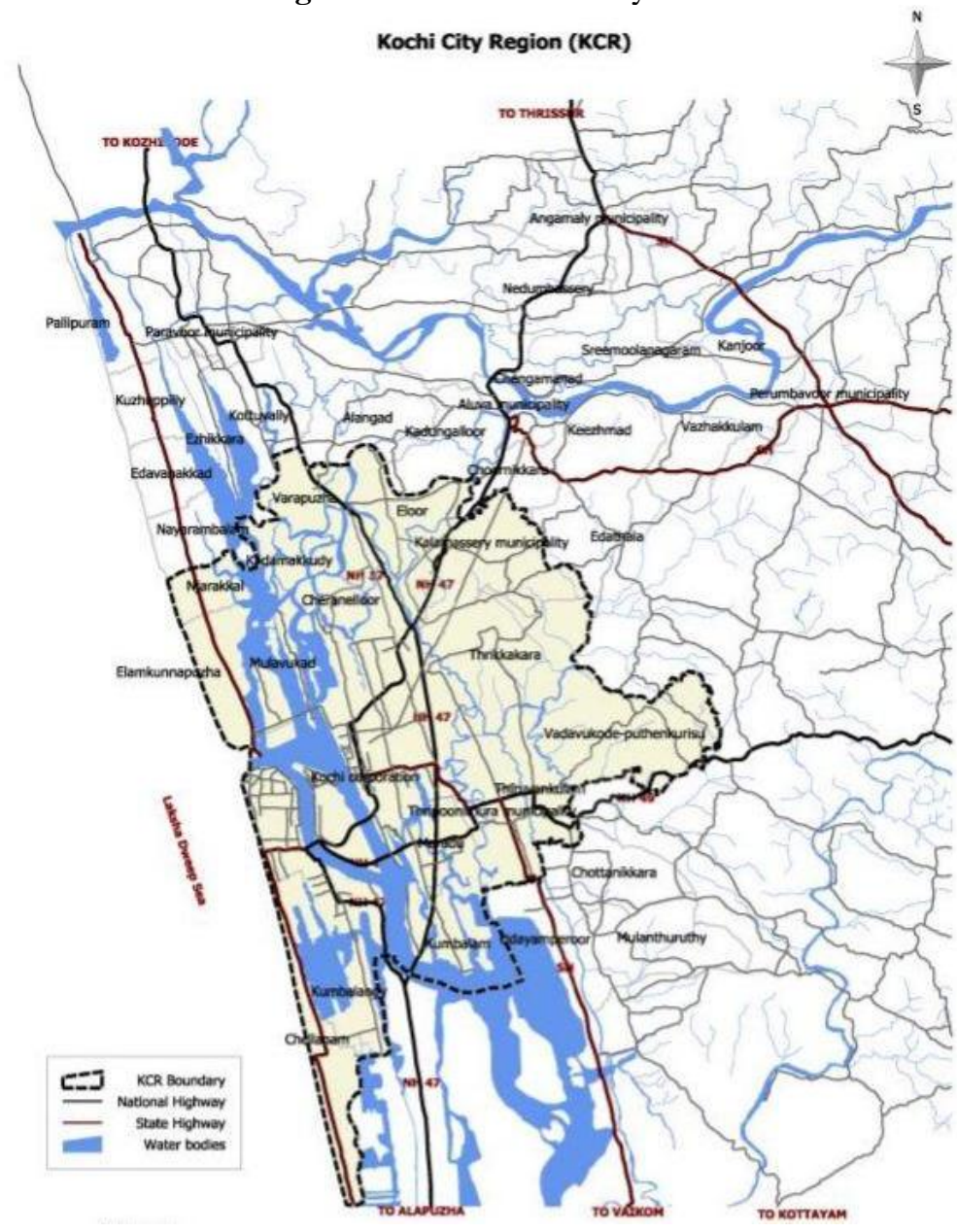

Figure 3: Kochi City Region

\section{Cycling Initiatives in Kochi}

The budget has stressed on green transportation facilities in Kochi. In order to create a cycling-friendly environment in Kochi, the Cochin Smart Mission Limited (CSML) is developing cycle lanes throughout the smart roads. The cycle lanes are being built on these roads as part of the 'India Cycles 4 Change Challenge' with the support of the German development agency, GIZ. Kochi is one of the 107 cities to have registered for the India Cycles4Change Challenge, an initiative of Smart Cities Mission, Ministry of Housing and Urban Affairs, Government of India. Since the outbreak of 
Covid 19, Cycles continue to be in high demand in the city. Despite the shortage in availability of cycles, more people are keen to take up cycling to stay fit.

\section{Analysis of Existing Determinants}

The various determinants for bicycle planning are discussed. The demand-based determinants include Land use and Population while the supply-based determinants include transportation network, locations of transit hubs, schools, recreational areas, existing cycling infrastructure etc.

\subsection{Existing Land use}

Analysis of the land utilization pattern shows that the areas on the north-eastern and western part of this region vary significantly, as the western part comprises of islands surrounded by water bodies and fragmented by canals and backwaters. The per capita developed land holding is only 117 sq.m in the city and an average of 175 sq.m in the Kochi City Region. The existing land use pattern has resulted from the complex interactions of various factors in the urban structure.

\subsection{Population}

Kochi city Region comprises of Kochi City and its immediate influence areas covering an area of 369.72 Sq.km with a population of 11.79 Lakh in 2011.The population of Kochi City Region has increased from 11.64 Lakh in 2001 to 11.79 Lakh in 2011 with a very low decadal growth rate of $1.3 \%$. Both the municipalities of Thripunnithura and Kalamassery have registered a higher growth rate of $15.9 \%$ and $12.6 \%$ respectively. With the investments in IT and port sector, it is anticipated that the growth rates would shoot up especially in the Kochi City Region.

\subsection{Existing Transportation Network}

Kochi is well connected to other parts of the country and state through an extensive network of National Highways and State Highways, there are three important National Highways NH 47, NH 17, NH 49 that pass-through Kochi city and a link road which connects NH 47 and NH 49 known as 47- A. Kochi has a good network of inland waterway system consisting of backwaters, canals, lagoons and estuaries. National Waterway No.3 connecting Kollam and Kottappuram pass through the region.

The State Water Transport Department (SWTD), Kerala Shipping and Inland Navigation Corporation (KSINC) and private operators are providing passenger and cargo boat services to the adjoining islands and industrial centers. The metro covers a stretch of $25.6 \mathrm{~km}$ from Aluva to Petta and constitutes 22 stations at the major attraction and production locations along the alignment like the CUSAT University, Lulu Mall, JLN stadium, MG Road the commercial hub, Ernakulam South Railway station and Vytilla mobility hub.

\subsection{Existing Transportation Network}

Kochi is well connected to other parts of the country and state through an extensive network of National Highways and State Highways, there are three important National Highways NH 47, NH 17, NH 49 that pass-through Kochi city and a link road which connects NH 47.

\subsection{Locations of Recreational areas}

Only less than $1 \%$ of the area of the city falls under this category. However, the vast expanse of water sheet and agricultural land which constitute $39.44 \%$ of the area of Kochi City Region provide the lung space.

\subsection{Locations of schools}

Sree Rama Varma High School, Edappally High School, Government School-Kochi, and Govt Girls Higher Secondary School in Kacheripady are important government schools. Within the city borders and in the suburbs, the Kendriya Vidyalaya, Chinmaya Mission, and Bharatiya Vidya Bhavan manage various quasi-private charter schools. There are a number of entirely private schools in the area.

\subsection{Existing Cycling Infrastructure}

Non-motorised transport (NMT) has been getting a lot of attention in Kochi both for being eco-friendly and being a free ticket to good health. Kochi Metro Rail Limited has been in the forefront of providing such green transport options as feeder service for metro users. Their newest initiative in collaboration with Cochin Smart Mission Limited (CSML) has picked Ahmedabad-based MYBYK, a bicycle renting start-up, that will give Kochiites easy access to a bicycle they can use and keep in the city. The company has deployed 300 cycles across 35 MYBYK Hubs spread across the city and plans to add another 700 cycles and $65+$ Hubs over the phase.

To create a cycling-friendly environment in Kochi, the Cochin Smart Mission Limited (CSML) is developing temporary cycle lanes throughout the smart roads. The cycle tracks are aimed at encouraging people to use the clean and healthy mode of transport in daily life, a statement from CSML said. The agency has decided to elevate six arterial roads in the city to the status if smart roads. They include Abraham Madamakkal Road, Banerjee Road, Shanmugham Road, Park Avenue Road, Durbar Hall Road and South Railway Station Road. The cycle lanes are being built on these roads as part of the 'India Cycles 4 Change Challenge'.

\section{Bicycle route suitability assessment}

In order to identify most suitable areas to build bicycle routes, the overlay analysis is performed using city-scaled thematic maps in GIS. The overlay map identifies the most suitable areas by summing the highest level of suitability of each data for bicycle route across the city. In order to make spatial decisions by using multi-criteria in GIS, it is required 
to make spatial data identical. The spatial data are reclassified into Five intervals in the form of thematic map.

The classification labelled as 1-5 scale value and 1 denoting "Least suitable area" and 5 denoting "Most suitable area" for cycling. Within the demand side, the data on the spatial distribution of population and the land use characteristics are used. it is assumed that the areas with highest density of nonresidential uses including business districts, commercial and schools creates more demand for cycling as destination points.
The most suitable area for cycling routes is classified as

- Areas Passes within two kilometers of a transit center (metro, ferry)

- Passes within two kilometers of a high school

- Passes within two kilometers of an elementary school or middle school

- Provides access to a recreation area or otherwise serves a recreation purpose.

- Areas having higher population density.

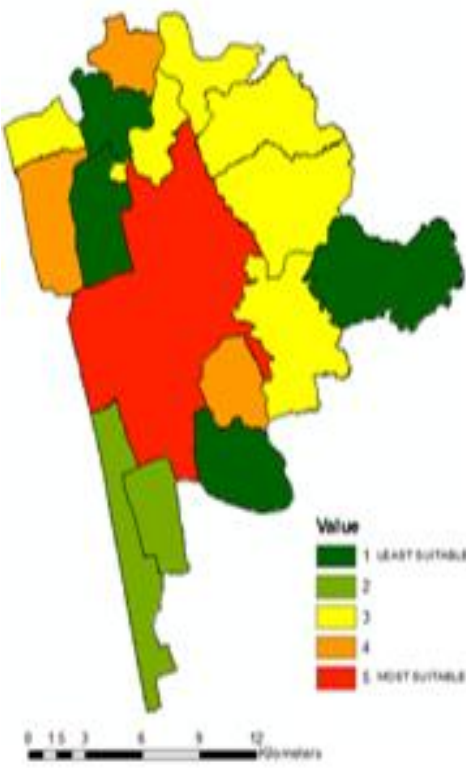

POPULATION DENSITY

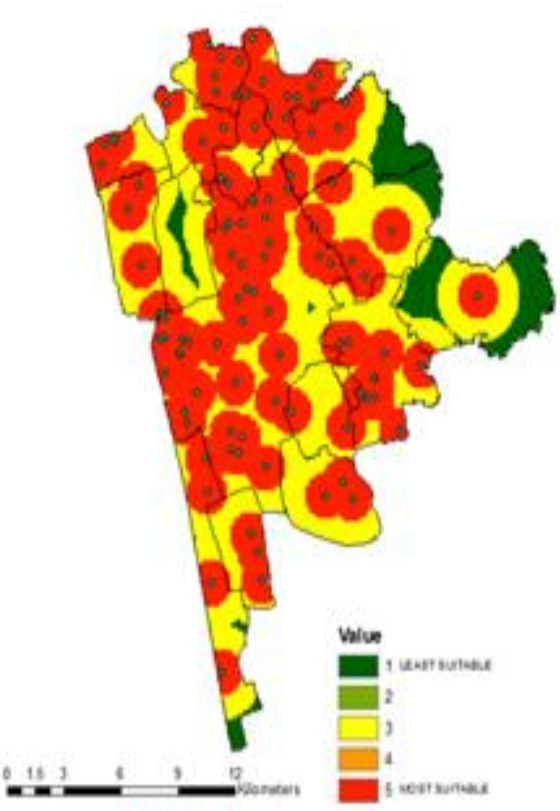

SCHOOLS

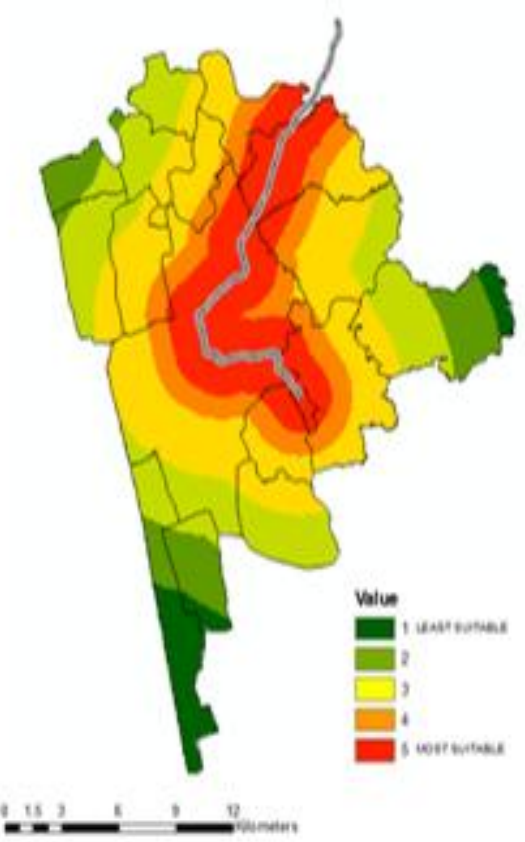

METRO ALIGNMENT

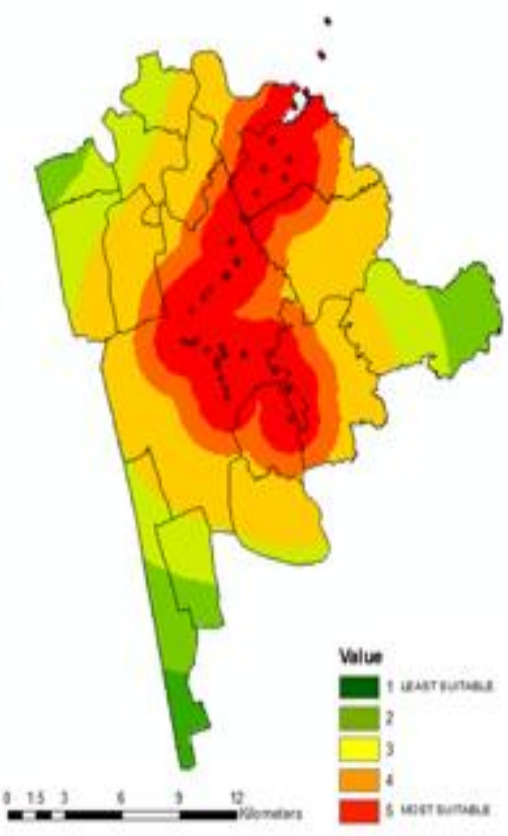

MYBYK CYCLE SHARING

LOCATION

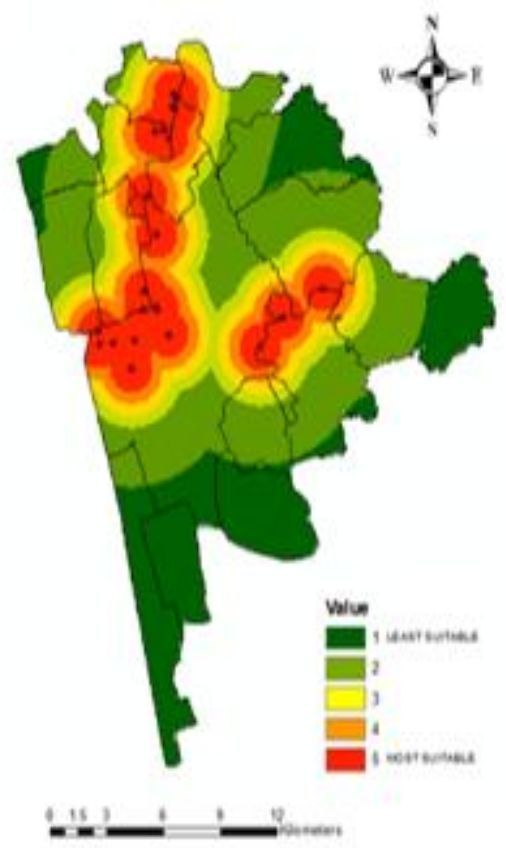

FERRY STOPS

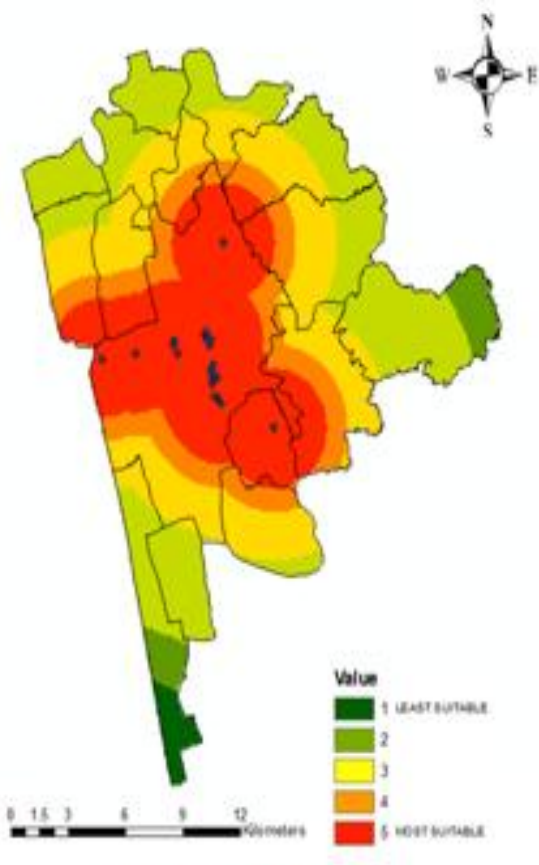

PARKS LOCATION

Figure 4: Thematic maps used for overlay analysis in GIS 

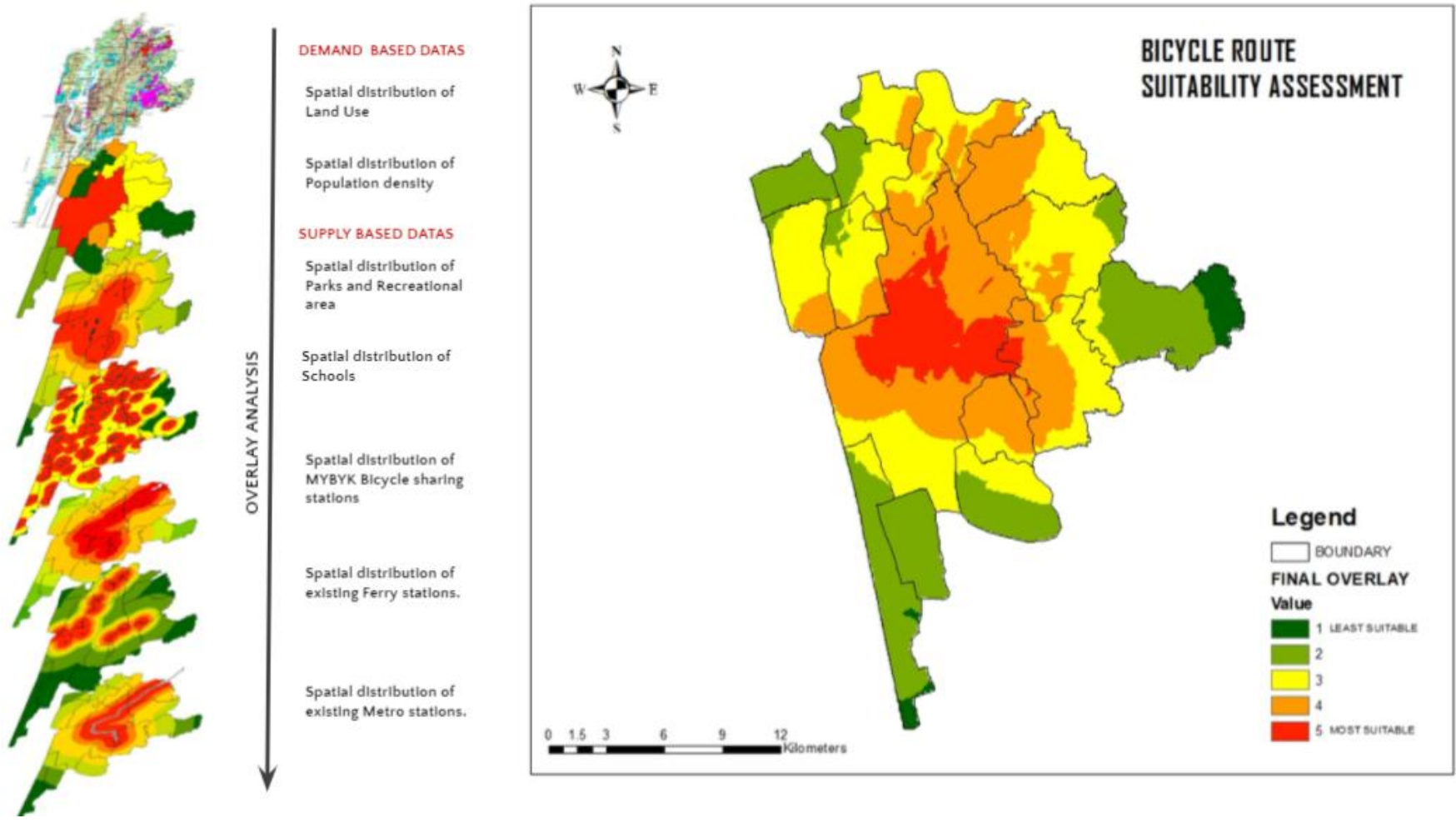

Figure 4: Bicycle route suitability assessment map

The overlay map detects the priority areas suitable for cycling routes by summing the highest level of suitability of each data for bicycle route across the city. The Bicycle route suitability assessment map detects the suitable or most priority area to be in the Kochi corporation area. The central business district (CBD) area comes under the priority area. Major recreational areas such as Subash park, Park Avenue, Panampilly central park etc are the major point of interests.

\section{Conclusion}

The study determines the priority areas for bicycle route using multi-criteria decision analysis in GIS environment. Bicycle route planning requires dealing with many different parameters and spatial data at the same time and GIS provides a versatile environment to analyze all these data simultaneously.

Spatial distribution of major land uses, recreational areas, schools, total population are summed by overlay method to detect most suitable area at city scale. The priority area for cycling is identified through the overlay analysis using multi criteria decision analysis.

Overlay method is used for the city level analysis and it is required to use network analysis to manage detailed data of built-environment at neighborhood level. The bicycle route network can be further identified through Network analysis which is not discussed in this paper. The proposed priority cycling routes are identified through analysing the existing point of interests, road width and traffic flow. The GIS-Multi criteria decision analysis is an effective method to determine the cycling routes in an already developed urban area.

\section{References}

[1] Aultman-Hall, L., Hall, F., Baetz, B., 1997. Analysis of bicycle commuter routes using geographic information systems: implications for bicycle planning. Transportation Research Record: Journal of the Transportation Research Board, (1578), pp.102-110.

[2] CMP, U. (2017). Comprehensive Mobility Plan for Greater Kochi Region, Volume 1. Kochi: KMRL.

[3] Huang, Y. and Ye, G., 1995. Selecting bicycle commuting routes using GIS. Berkeley Planning Journal, 10(1).

[4] Malczewski, J., 2006. GIS-based multi-criteria decision analysis: a survey of the literature. International Journal of Geographical Information Science, 20(7), pp.703726

[5] Milakis, D. and Athanasopoulos, K., 2014. What about people in cycle network planning? Applying participative multi-criteria GIS analysis in the case of the Athens metropolitan cycle network. Journal of Transport Geography, 35, pp.120-129.

[6] Rybarczyk, G. and Wu, C., 2010. Bicycle facility planning using GIS and multi-criteria decision analysis. Applied Geography, 30(2), 282-293.

[7] Segadilha, A.B.P. and da Penha Sanches, S., 2014. Analysis of bicycle Commuter Routes using GPSs and GIS. Procedia-Social and Behavioral Sciences, 162, pp.198-207.

[8] Sevim, Pelin \& Senol, Fatma \& Özçam, Zeynep. (2020). Bicycle Route Infrastructure Planning Using GIS in an Urban Area: The Case of İzmir. Journal of Planning. 30. 313-327.

[9] Terh, Shin \& Cao, Kai. (2018). GIS-MCDA based cycling paths planning: a case study in Singapore. Applied Geography. 94. 10.1016/j.apgeog.2018.03.007 